\title{
Mempersiapkan SMP Muhammadiyah 1 Malang Meraih Predikat Sekolah Adiwiyata
}

\section{Tutut Indria Permana, Diani Fatmawati}

Prodi Pendidikan Biologi, FKIP, Universitas Muhammadiyah Malang, Jalan Raya Tlogomas No. 246, Malang, Indonesia 65144

\section{Email Korespondensi: tutut.indria@umm.ac.id}

\begin{tabular}{|c|c|}
\hline Article Info & bstract \\
\hline $\begin{array}{l}\text { Article History } \\
\text { Received: } 2020-10-22 \\
\text { Revised: } 2020-10-29 \\
\text { Published: } 2020-10-30\end{array}$ & \multirow{2}{*}{$\begin{array}{l}\text { Preparing SMP Muhammadiyah } 1 \text { Malang Achieving Adiwiyata. SMP } \\
\text { Muhammadiyah } 1 \text { Malang needs to actualize programs promoted by the } \\
\text { government to be able to compete with other schools, one of which is to } \\
\text { achieve Adiwiyata. The low level of individual environmental awareness has } \\
\text { been increasing environmental damage. Hence, this awareness is compulsory } \\
\text { to be introduced early in school. Environmental awareness reflects students } \\
\text { who have the insight to maintain the environment based on Islamic teachings. } \\
\text { This community service program aimed at guiding as well as accompanying } \\
\text { SMP Muhammadiyah } 1 \text { Malang to prepare their school to enact Adiwiyata } \\
\text { School recognition. The assistance given was giving an introduction of } \\
\text { Adiwiyata School and socializing the criteria assessed. Eventually, several } \\
\text { recommendations given by the community service team were proposing 1) } \\
\text { school management, 2) generating pilot project classes, and 3) planning } \\
\text { programs which support the school to get Adiwiyata School recognition. }\end{array}$} \\
\hline $\begin{array}{l}\text { Keywo } \\
\text { Adiwiy } \\
\text { enviror } \\
\text { student }\end{array}$ & \\
\hline Infor & bstrak \\
\hline $\begin{array}{l}\text { Sejarah Artikel } \\
\text { Diterima: } 22-10-202 \\
\text { Direvisi: } 29-10-202 \\
\text { Dipublikasi: } 30-10-2\end{array}$ & \multirow{2}{*}{$\begin{array}{l}\text { SMP Muhammadiyah } 1 \text { Malang perlu merealisasikan program-program yang } \\
\text { digalakkan pemerintah agar mampu bersaing dengan sekolah lain, salah } \\
\text { satunya menjadi sekolah adiwiyata. Hal tersebut terkait dengan kerusakan } \\
\text { lingkungan yang semakin parah akibat ulah manusia. Hal itu terjadi karena } \\
\text { rendahnya karakter kesadaran lingkungan individu yang perlu dikenalkan sejak } \\
\text { dini dari sekolah. Kesadaran lingkungan mencerminkan siswa yang memiliki } \\
\text { wawasan untuk melestarikan lingkungan sesuai dengan ajaran Islam. Program } \\
\text { pengabdian masyarakat ini bertujuan mendampingi SMP Muhammadiyah } 1 \\
\text { Malang menjadi sekolah Adiwiyata. Desain pendampingan yang dilakukan } \\
\text { adalah memberikan pengenalan dan pelaksanaan manajemen sekolah agar } \\
\text { mampu mempersiapkan pengajuan untuk mendapatkan penghargaan sebagai } \\
\text { sekolah Adiwiyata. Rekomendasi yang diberikan oleh tim pengabdi adalah 1) } \\
\text { manajemen sekolah, 2) pembentukan kelas sebagai pilot project, 3) } \\
\text { perancanaan program-program yang mendukung sekolah untuk mendapatkan } \\
\text { pengakuan Sekolah Adiwiyata. }\end{array}$} \\
\hline $\begin{array}{l}\text { Kata I } \\
\text { karakt } \\
\text { peduli } \\
\text { sekola }\end{array}$ & \\
\hline
\end{tabular}

Sitasi: Permana I.T., \& Fatmawati D., (2020) Mempersiapkan SMP Muhammadiyah 1 Malang Meraih Predikat Sekolah Adiwiyata. Sasambo: Jurnal Abdimas (Journal of Community Service). 2(3), 180-187 DOI : 10.36312/sasambo.v2i3.310

\section{PENDAHULUAN}

Keberadaan SMP Muhammadiyah 1 Malang menjadi salah satu sekolah SMP swasta yang diperhitungkan oleh masyarakat Kota Malang dan daerah sekitarnya. SMP Muhammadiyah 1 Malang yang berdiri di atas lahan seluas $2.535 \mathrm{~m}^{2}$ ini berada di wilayah Kecamatan Klojen, tepatnya di Jalan Brigjen Slamet Riadi No. 134 Kota Malang. Letak sekolah yang strategis berada di daerah pusat kota menjadi salah satu keuntungan dalam 
menjaring siswa. Letak sekolah yang mudah dijangkau oleh kendaraan pribadi dan juga angkutan umum menjadi salah satu alternatif pilihan sekolah lanjutan. Tetapi selain menjadi keuntungan, letak di tengah kota juga menjadi tantangan, karena keberadaan sekolah negeri maupun swasta banyak berdiri di sekitarnya.

Agar mampu bersaing dengan sekolah lain, SMP Muhammadiyah 1 Malang perlu mengaktualisasikan program-program yang sedang digalakkan oleh pemerintah, salah satunya adalah menjadi sekolah Adiwiyata. Sekolah Adiwiyata (Green School) merupakan salah satu program Kementrian Lingkungan Hidup dan Kementrian Pendidikan Nasional yang memiliki tujuan untuk mendorong terciptanya pengetahuan serta kesadaran warga sekolah dalam pelestarian lingkungan hidup. Pada faktanya, masih sangat sedikit sekolah Muhammadiyah di Kota Malang yang terakui sebagai sekolah Adiwiyata. Mengacu pada beberapa sumber, hanya ada 2 sekolah Muhammadiyah yang mendapatkan anugrah sekolah Adiwiyata, yakni SD Muhammadyah 8 (Politikamalang, 2019) dan SD Muhammadiyah 4 (Radarmalang, 2019). Dengan demikian, berbagai upaya untuk meraih pengakuan pemerintah, khususnya anugrah sekolah Adiwiyata, dalam rangka meningkatkan daya saing sekolah-sekolah Muhammadiyah termasuk SMP Muhammadiyah 1 Malang penting untuk dilakukan.

Pendidikan lingkungan hidup dalam program sekolah Adiwiyata dapat membantu dalam pembentukan karakter peduli lingkungan siswa di sekolah. Karakter peduli lingkungan dapat dikembangan dengan adanya pendidikan lingkungan. Pendidikan lingkungan mengacu pada upaya terorganisir untuk mengajarkan bagaimana fungsi lingkungan dan mengajarkan bagaimana manusia dapat mengelola perilaku dan ekosistem untuk hidup secara berkelanjutan (Boeve-de Pauw, Donche, \& Van Petegem, 2011; Cheeseman \& Wright, 2019; do Carmo Galiazzi et al., 2018; Genc, 2015; Steele, Hives, \& Scott, 2016). Pendidikan lingkungan penting dalam menanamkan rasa peduli pada alam yang melekat diantara masyarakat serta meningkatkan kesadaran lingkungan (Aliman, Budijanto, Sumarmi, \& Astina, 2019; Bergman, 2016). Pendidikan lingkungan juga diharapkan dapat berperan dalam upaya menjaga kualitas hidup masyarakat di masa depan. Dengan demikian, karakter peduli lingkungan perlu ditanamkan dari tingkat sekolah (Al-anwari, 2014; Munawar, Heryanti, \& Miarsyah, 2019; Permana \& Ulfatin, 2018; Widodo, 2017).

Tidak dapat dipungkiri fakta bahwa semakin parahnya kerusakan lingkungan yang terjadi merupakan akibat kegiatan manusia. Menurut Baharudin (2017) kerusakan lingkungan semakin parah ketika manusia menjadikannya sebagai objek yang perlu dieksploitasi tanpa melakukan berbagai pertimbangan terhadap resiko yang ditimbulkan. Hal ini merupakan kosekwensi dari rendahnya karakter peduli lingkungan pada individu (Alanwari, 2014; Asy'ari \& Abidin, 2019; Baharudin, 2017).

Pendidikan karakter peduli lingkungan juga didukung oleh misi sekolah yaitu "Terbentuknya manusia bertaqwa, terampil berkarya, berwawasan" dengan visi "Menumbuhkan sikap penghayatan pengalaman ajaran agama dalam kehidupan sehari-hari". Karakter peduli lingkungan mencerminkan siswa yang berwawasan untuk menjaga kelestarian lingkungan sesuai ajaran Islam. Hasil observasi ke sekolah mitra menunjukkan bahwa saat ini, SMP Muhammadiyah memliki 26 guru dan tenaga kependidikan yang melayani 7 kelas siswa. Selain itu, SMP Muhammadiyah 1 juga terletak satu lokasi dengan SMA Muhammadiyah. Sejauh ini, sekolah belum pernah melakukan perencanaan tata kelola sekolah Adiwyata yang secara spesifik membidik berbagai kriteria sekolah Adiwyata yang telah ditetapkan oleh pemerintah. Kondisi ini memberikan tantangan tersendiri dalam menyelenggarakan program-program sekolah Adiwyata sekalipun komitmen sekolah sangat besar untuk mencapainya.

Berdasarkan diskusi dengan pihak sekolah, tim pengabdi beserta pihak sekolah bersepakat bahwa untuk mencapai predikat sekolah adiwiyata, memang perlu dilakukan perencanaan yang matang sejak saat ini yang langsung membidik berbagai kriteria yang telah 
ditentukan oleh pemerintah. Dengan demikian pendampingan SMP Muhammadiyah 1 Malang menuju sekolah Adiwiyata perlu dilakukan.

Pengabdian ini memberikan kontribusi dalam bentuk pendampingan untuk memberikan pengenalan dan implementasi managemen sekolah dalam rangka mempersiapkan pengajuan diri untuk dianugrahi sebagai sekolah Adiwiyata. Hal ini tentu dengan menciptakan kondisi yang lebih baik bagi pada sekolah untuk menjadi wadah pembelajaran serta penyadaran segenap warga sekolah diantaranya siswa, guru, orang tua/wali murid, dan juga lingkungan masyarakat demi terciptanya upaya pelestarian lingkungan hidupTujuan program pengabdian ini adalah untuk memberikan pendampingan kepada sekolah SMP Muhammadiyah 1 Malang dalam rangka mempersiapkan perencanaan sekolah untuk mencapai pengakuan sekolah Adiwyata.

\section{METODE}

Permasalahan berkaitan dengan pentingnya aktualisasi sekolah menjadi Sekolah Adiwiyata untuk meningkatkan karakter peduli lingkungan pada siswa. Salah satu upaya yang dilakukan adalah dengan mengadakan kegiatan pendampingan dalam mempersiapkan sekolah menuju Sekolah Adiwiyata. Program pengabdian dilakukan di sekolah mitra yaitu SMP Muhammadiyah 1 Malang. Target program pengabdian ada dua yaitu: 1) mendukung persiapan menuju Sekolah Adiwyata dengan melakukan sosialisasi Sekolah Adiwiyata; dan 2) mensosialisasikan berbagai kriteria yang akan menjadi ukuran penilaian Sekolah Adiwiyata. Indikator ketercapaian program pengabdian ini adalah: 1) tersosialisasikannya gambaran yang jelas tentang Sekolah Adiwyata kepada pihak sekolah; 2) tersosialisasikannya kriteria-kriteria penilaian yang tercantum dalam instrumen penilaian Sekolah Adiwiyata. Subjek pengabdian adalah kepala sekolah dan guru SMP Muhammadiyah 1 Malang yang berjumlah 14 orang. Kegiatan pengabdian dilaksanakan selama 3.5 bulan. Instrumen untuk mengambil data terdiri dari lembar kuisioner dan kamera. Kuisioner digunakan untuk mengukur pengetahuan guru terkait sekolah adiwiyata dan mengidentifikasi penerapan indikator-indikator sekolah adiwiyata (pertanyaan kuisioner dicantumkan pada Tabel 1). Kamera digunakan untuk melakukan dokumentasi ketika proses pengabdian berlangsung. Metode pelaksanaan pengabdian yang telah didiskusikan dan disepakati bersama dengan sekolah mitra disajikan dalam Tabel 2.

Tabel 1. Pertanyaan yang digunakan dalam instrumen kuisioner

\begin{tabular}{|c|c|c|}
\hline No. & Indikator yang diukur & Pertanyaan kuisioner \\
\hline 1. & $\begin{array}{l}\text { Pengetahuan terkait } \\
\text { sekolah adiwiyata }\end{array}$ & $\begin{array}{l}\text { a. Apa yang Bapak/Ibu ketahui tentang sekolah Adiwiyata? } \\
\text { b. Terkait pembentukan sekolah Adiwiyata perlu dilakukan } \\
\text { atau tidak? Bagaimana pendapat Bapak/Ibu? }\end{array}$ \\
\hline 2. & $\begin{array}{l}\text { Penerapan indikator- } \\
\text { indikator sekolah } \\
\text { adiwiyata }\end{array}$ & $\begin{array}{l}\text { 1. Apakah pembelajaran di kelas mengintegrasikan penerapan } \\
\text { Perilaku Ramah Lingkungan Hidup (PRLH)? } \\
\text { 2. Apakah kegiatan ekstrakurikuler mengintegrasikan } \\
\text { penerapan PRLH? } \\
\text { 3. Apakah ada pengelolaan sampah di sekolah? } \\
\text { 4. Adakah kegiatan penanaman dan pemeliharaan } \\
\text { pohon/tanaman oleh warga sekolah? } \\
\text { 5. Apakah ada upaya konservasi air yang dilakukan di sekolah? } \\
\text { 6. Apakah ada upaya konservasi energi yang dilakukan di } \\
\text { sekolah? } \\
\text { 7. Apakah ada kegiatan yang menerapkan PRLH untuk } \\
\text { masyarakat sekitar Sekolah dan/atau di daerah? } \\
\text { 8. Apakah ada kegiatan kampanye dan/atau publikasi Gerakan } \\
\text { Peduli dan Berbudaya Lingkungan Hidup di Sekolah } \\
\text { (PBLHS)? } \\
\text { 9. Apakah sudah ada pembentukan dan/atau pemberdayaan } \\
\text { Kader Adiwiyata }\end{array}$ \\
\hline
\end{tabular}


Partisipasi yang diberikan mitra dalam pelaksanaan program pengabdian kelompok ini adalah: 1) menyediakan sumber daya manusia, yaitu semua warga skeolah untuk berpartisipasi aktif dalam mempersiapkan sekolah menuju Sekolah Adiwiyata; dan 2) menyediakan tempat dan ruang yang representatif untuk kelancaran pelaksanaan kegiatan pengabdian.

Tabel 2. Metode pelaksanaan pengabdian di MA Muhammadiyah 1 Malang

\begin{tabular}{|c|c|c|}
\hline No. & Nama Kegiatan & Target Luaran \\
\hline 1. & $\begin{array}{l}\text { Sosialisasi Program } \\
\text { kepada Pihak Sekolah }\end{array}$ & $\begin{array}{l}\text { Pemahaman dan kesepakatan bersama pihak sekolah untuk } \\
\text { menerapkan berbagai program yang berubungan dengan } \\
\text { indikator sekolah adiwiyata. }\end{array}$ \\
\hline 2. & $\begin{array}{l}\text { Pendampingan dalam } \\
\text { Persiapan Sekolah } \\
\text { Menuju Sekolah } \\
\text { Adiwiyata }\end{array}$ & $\begin{array}{l}\text { 1. Terbentuknya managemen sekolah yang mendukung } \\
\text { persiapan pengajuan Penghargaan Adiwiyata Kota. } \\
\text { 2. Terbentuknya beberapa kelas pilot project yang mendukung } \\
\text { program Adiwiyata seperti kelas bebas plastik dengan } \\
\text { menyediakan air minum dalam kelas dan menerapkan aturan } \\
\text { siswa harus membawa kotak makan dan botol air minum. } \\
\text { 3. Tersusunnya program-program sekolah yang mendukung } \\
\text { Sekolah Adiwiyata, seperti pengadaan panen air hujan, } \\
\text { sumur resapan (biopori), dan sekolah bebas plastik. }\end{array}$ \\
\hline
\end{tabular}

\section{HASIL DAN PEMBAHASAN}

\section{Sosialisasi Program kepada Pihak Sekolah}

Sebelum melakukan sosialisasi terkait pelaksanaan program pengabdian masyarakat di SMP Muhammadiyah 1 Malang dilakukan pengukuran pengetahuan guru terkait sekolah adiwiyata dan mengidentifikasi penerapan indikator-indikator sekolah adiwiyata. Hasil kuisioner yang diberikan kepada pihak sekolah menunjukkan bahwa 85,7\% guru memahami definisi sekolah adiwiyata. Selanjutnya $78,6 \%$ guru menyatakan pembentukan sekolah Adiwiyata perlu dan penting dilakukan, dengan memulai dari program-program sederhana terebih dahulu. Hasil identifikasi penerapan indikator-indikator sekolah adiwiyata disajikan pada Tabel 3.

Tabel 3. Hasil kuisioner terkait penerapan indikator sekolah adiwiyata

\begin{tabular}{|c|c|c|}
\hline \multirow{2}{*}{ Indikator } & \multicolumn{2}{|c|}{ Persentase Jawaban } \\
\hline & Ya & Tidak \\
\hline $\begin{array}{l}\text { 1. Apakah pembelajaran di kelas mengintegrasikan penerapan } \\
\text { Perilaku Ramah Lingkungan Hidup (PRLH)? }\end{array}$ & 50,0 & 50,0 \\
\hline $\begin{array}{l}\text { 2. Apakah kegiatan ekstrakurikuler mengintegrasikan penerapan } \\
\text { PRLH? }\end{array}$ & 35,7 & 64,3 \\
\hline 3. Apakah ada pengelolaan sampah di sekolah? & 14,3 & 85,7 \\
\hline $\begin{array}{l}\text { 4. Adakah kegiatan penanaman dan pemeliharaan pohon/tanaman } \\
\text { oleh warga sekolah? }\end{array}$ & 78,6 & 21,4 \\
\hline 5. Apakah ada upaya konservasi air yang dilakukan di sekolah? & 57,1 & 42,9 \\
\hline 6. Apakah ada upaya konservasi energi yang dilakukan di sekolah? & 7,1 & 92,9 \\
\hline $\begin{array}{l}\text { 7. Apakah ada kegiatan yang menerapkan PRLH untuk masyarakat } \\
\text { sekitar Sekolah dan/atau di daerah? }\end{array}$ & 21,4 & 78,6 \\
\hline $\begin{array}{l}\text { 8. Apakah ada kegiatan kampanye dan/atau publikasi Gerakan Peduli } \\
\text { dan Berbudaya Lingkungan Hidup di Sekolah (PBLHS)? }\end{array}$ & 57,1 & 42,9 \\
\hline $\begin{array}{l}\text { 9. Apakah sudah ada pembentukan dan/atau pemberdayaan Kader } \\
\text { Adiwiyata }\end{array}$ & 42,9 & 57,1 \\
\hline
\end{tabular}

Kegiatan sosialisasi (Gambar 1) dilakukan pada bulan Juli 2020 dengan memberikan pengenalan ke sekolah mitra terkait program Sekolah Adiwiyata yang diselenggarakan oleh Kementerian Lingkungan Hidup dan Kementerian Pendidikan Nasional. Sekolah adiwiyata 
bertujuan untuk mendorong terciptanya pengetahuan serta juga kesadaran warga sekolah dalam pelestarian lingkungan hidup. Hasil pengisian kuisioner menunjukkan bahwa guruguru di SMP Muhammadiyah 1 Malang sudah memiliki pemahaman terkait makna dari Sekolah Adiwiyata. Pengetahuan guru ini penting dalam menunjang peran guru dalam memberikan kontribusinya dalam realisasi program Sekolah Adiwiyata. Terkait dengan hal ini Setiyowati (2017) melaporkan sebagai hasil penelitiannya bahwa guru-guru memberdayakan diri mereka dalam upaya pencapaian Sekolah Adiwiyata adalah dengan kompetensi yang mereka miliki. Bahkan peneliti berupaya menggunakan metode tertentu untuk meningkatkan pengetahuan guru tentang Sekolah Adiwiyata (Supriadi, 2020).

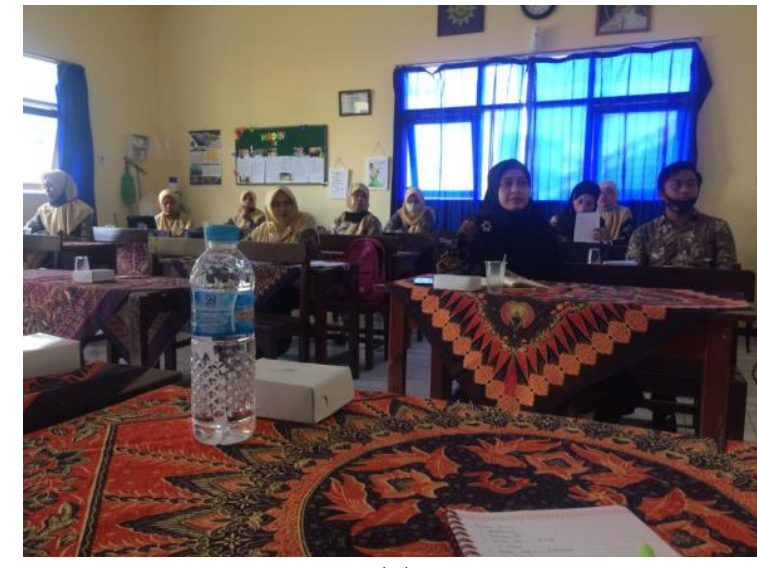

(a)

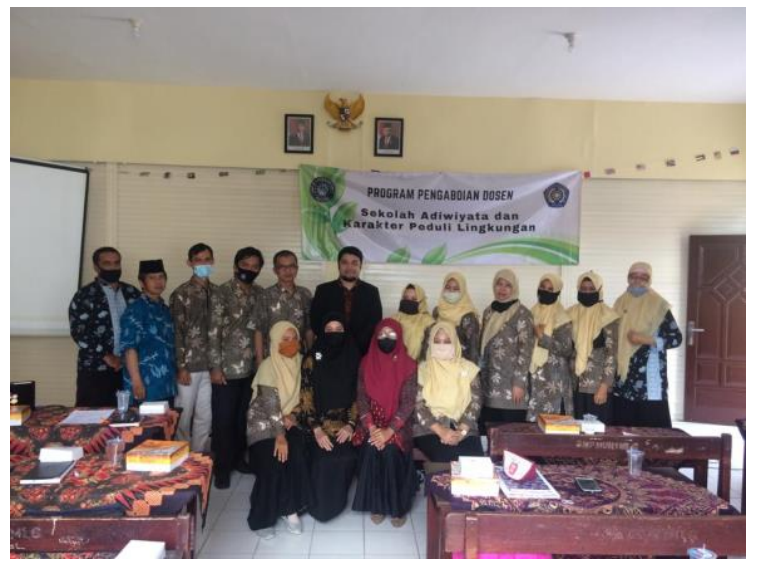

(b)

Gambar 1. Kegiatan sosialisasi program pengabdian, (a) pemaparan materi terkait sekolah adiwiyata yang ditunjukkan saat, (b) dokumentasi setelah sosialisasi.

Tabel 3 merupakan hasil pengisian kuisioner terkait penerapan indikator sekolah adiwiyata. Hasil survey pada tabel tersebut menunjukkan bahwa di SMP Muhammadiyah 1 Malang sebagian $(50 \%)$ kegiatan pembelajaran sudah mengintegrasikan penerapan PRLH dalam kegiatan pembelajaran di kelas. Namun hanya 35,7\% integrasi PRLH dalam kegiatan ekstrakurikuler (Lihat Tabel 3). Hal ini perlu dievaluasi dengan melakukan peningkatan integrasi PRLH. Indikator lainnya yang paling rendah adalah terkait konservasi energi yang dilakukan di sekolah $(7,1 \%)$, disusul dengan indikator pengelolaan sampah di sekolah yang juga cukup rendah yaitu hanya $14,3 \%$. Urutan ketiga terendah adalah adanya kegiatang penerapan PRLH untuk masyarakat sekitar sekolah dan/atau di daerah sekitar sekolah $(21,4 \%)$. Selanjutnya pembentukan atau pembedayaan kader adiwiyata juga masih rendah $(42,9 \%)$. Fakta ini menunjukkan bahwa kegiatan-kegiatan sederhana untuk membiasakan warga sekolah memiliki rasa peduli pada lingkungan masing belum diupayakan dengan optimal. Maka, program yang bisa dilakukan di sekolah adalah dengan mengintegrasikan penerapan PRLH dalam pembelajaran kurikuler (dalam kelas) dan ekstrakurikuler. Dengan demikian, sekolah memiliki pendidikan lingkungan dapat memberdayakan sikap peduli lingkungan pada siswanya (Boeve-de Pauw \& Van Petegem, 2011). Adanya sikap peduli lingkungan siswa ini sangat penting dan berkaitan dengan kemampuan kognitif siswa (Schumm \& Bogner, 2016). Namun demikian integrasi PRLH ini sebenarnya tidak cukup hanya pada proses pembelajaran, namun harus ada kebijakan-kebijakan sekolah yang mendukung hal tersebut. Dengan demikian perlu kesepakatan bersama pihak sekolah dengan stakeholder untuk merumuskan kebijakan yang menyangkut penerapan PRLH dalam kurikulum sekolah sehingga mendukung perwujudan Sekolah Adiwiyata seperti misalnya pengalokasian dana untuk menunjang kegiatan PRLH, perbaikan infrastruktur sekolah yang kompatibel dengan PRLH, dan sebagainya. 
Indikator lainnya yang sudah dilakukan di SMP Muhammadiyah 1 Malang (Lihat Tabel 3 ) dengan persentase diatas $50 \%$ meliputi upaya konservasi air $(57,1 \%)$, melakukan kegiatan kampanye dengan berpartisipasi dalam Green School Festival (57,1\%), dan melakukan penanaman serta pemeliharaan tanaman oleh warga sekolah $(78,6 \%)$. Indikator-indikator yang sudah ada bisa lebih ditingkatkan dan dilengkapi dengan kegiatan-kegiatan lain yang mendukung seperti pengadaan taman vertical untuk memperluas area hijau, pendokumentasian regulasi atas kegiatan yang telah berjalan maupun yang ada dalam perencaan, dan sebagainya. Kegiatan sosialisasi program pengabdian di SMP Muhammadiyah 1 Malang ini, selain memberikan pengenalan terkait Sekolah Adiwiyata, juga memberikan saran-saran kepada pihak sekolah untuk melakukan pengembangan sekolah dengan kegiatan-kegiatan yang mendukung pendidikan lingkungan. Saran kegiatan jangka pendek yang diberikan oleh tim pengabdi adalah pendokumentasian berbagai kegiatan yang telah terlaksana serta kesesuaiannya dengan berbagai kriteria penilaian Sekolah Adiwiyata, serta perencanaan program pada kriteria yang belum terpenuhi oleh sekolah.

\section{Pendampingan dalam Persiapan Sekolah Menuju Sekolah Adiwiyata}

Pada kegiatan pendampingan dalam persiapan SMP Muhammadiyah 1 Malang menuju Sekolah Adiwiyata, seluruh target telah 100\% terpenuhi, baik target pertama maupun kedua. Target pertama yaitu sosialisasi pengenalan Sekolah Adiwiyata telah terlaksana dengan disampaikannya materi tentang deskripsi secara general tentang Sekolah Adiwiyata kepada pihak sekolah. Sosialisasi ini bertujuan untuk memberikan pengenalan dan mengingatkan kembali tentang konsep Sekolah Adiwiyata, serta meluruskan kesalahan konsep Sekolah Adiwiyata jika ada. Selain itu, pengenalan ini juga menguatkan motivasi kepada pihak sekolah untuk merealisasikan pencapaian predikat Sekolah Adiwyata ini bagi sekolah.

Target kedua yaitu mensosialisasikan berbagai kriteria yang akan menjadi ukuran penilaian Sekolah Adiwiyata. Penggambaran detail tentang kriteria penilaian ini bertujuan agar pihak sekolah mulai memahami kriteria penilaian Sekolah Adiwiyata. Hal ini diharapkan dapat menjembatani antara harapan sekolah untuk meraih predikat Sekolah Adiwiyata dengan berbagai kebijakan sekolah terkait perencanaan kegiatan-kegiatan sekolah untuk memenuhi berbagai kriteria penilaian Sekolah Adiwiyata.

Pendampingan yang dilakukan oleh tim pengabdi masih terbatas pada rekomendasirekomendasi kebijakan yang dapat direncanakan oleh sekolah. Pertama, pembentukan managemen sekolah yang mendukung persiapan pengajuan Penghargaan Adiwiyata Kota. Tim pengabdi memberikan gambaran pula bahwa proses ini membutuhkan waktu yang tidak sebentar karena harus melibatkan stakeholder dan pemangku kepentingan sekolah untuk melakukan perubahan pada kebijakan maupun kurikulum sekolah.

Kedua, pembentukan beberapa kelas pilot project yang mendukung program Sekolah Adiwiyata seperti kelas bebas plastik dengan menyediakan air minum dalam kelas dan menerapkan aturan siswa harus membawa kotak makan dan botol air minum sendiri. Dalam kondisi pandemik COVID-19 seperti saat ini dan belum jelas kapan akan berakhir, maka pihak sekolah dapat berupaya melakukan integrasi PRLH dalam bentuk video maupun pesan langsung yang disampaikan oleh guru saat melaksanakan pembelajaran daring bersama siswa. Pesan yang disampaikan terkait dengan pengelolaan sampah, pemeliharaan tanaman, konservasi air, dan konservasi energi. Hal ini sebagai upaya untuk melatih siswa untuk terbiasa peduli terhadap lingkungan. Seperti yang dijelaskan oleh Gould, Ardoin, Thomsen, dan Wyman Roth (2019) bahwa sikap peduli lingkungan akan terbentuk jika seseorang terbiasa melakukannya dalam kegiatan sehari-hari. Selanjutnya untuk pembentukan kelas pilot project akan dilakukan ketika siswa kembali belajar di sekolah.

Rekomedasi ketiga dari tim pengabdi adalah penyusunan program-program sekolah yang mendukung Sekolah Adiwiyata seperti pengadaan panen air hujan, sumur resapan (biopori), dan sekolah bebas plastik. Sedangkan program-program pengembangan lain yang 
sudah ada di sekolah, harus terus dikembangkan. Misalnya upaya pengelolaan sampah, namun masih terbatas pada pemisahan jenis sampah dapat dikembangkan dengan pengolahan sampah yakni sampah organik yang dimanfaatkan kembali dalam bentuk pupuk. Program lain berupa konservasi air dan energi yang perlu dipertegas dalam bentuk himbauan-himbauan yang ditunjukkan secara nyata pada warga sekolah dalam bentuk stiker dinding atau yang lainnya. Hal ini dilakukan untuk menanaman rasa peduli terhadap lingkungan baik pada siswa maupun guru di sekolah.

Beberapa rekomendasi yang telah diberikan oleh tim pengabdi telah direspon dengan positif oleh pihak sekolah yang dalam hal ini diwakili oleh Kepala Sekolah dan beberapa guru SMP Muhammadiyah 1 Malang. Dengan demikian, keberlanjutan program pengabdian ini akan dapat ditindaklanjuti dengan program pengabdian tahun berikutnya dalam bentu realisasi beberapa rekomendasi yang telah ditawarkan.

\section{KESIMPULAN}

Kegiatan program pengabdian yang dilakukan di SMP Muhammadiyah 1 Malang ini menghasilkan kegiatan-kegiatan awal di sekolah yang mendukung perwujudan sekolah Adiwiyata, seperti integrasi PRLH pada kegiatan kurikuler dan ekstrakurikuler, pengelolaan sampah, pemeliharaan tanaman, konservasi air dan konservasi energy. Namun target program pengabdian masih belum sepenuhnya tercapai dan akan dilanjutkan oleh pihak sekolah dengan berbagai pertimbangan-pertimbangan.

\section{SARAN}

Sebagai upaya tindak lanjut dari program pengabdian yang telah dilakukan, perlu tetap melanjutkan proses pendampingan di SMP Muhammadiyah 1 Malang sampai sekolah tersebut siap untuk pengajuan diri untuk dianugrahi sebagai sekolah adiwiyata. Masih banyak hal-hal yang terkait managemen sekolah yang perlu direkonstruksi dan disepakati bersama dengan stakeholder dan pemangku kepentingan untuk menuju sekolah adiwiyata

\section{UCAPAN TERIMA KASIH}

Ucapan terimakasih disampaikan kepada Direktorat Penelitian dan Pengabdian Masyarakat Universitas Muhammadiyah Malang (DPPM-UMM) yang telah memberikan dana untuk kegiatan Pengabdian Kelompok di SMP Muhammadiyah 1 Malang pada Tahun 2020 dengan nomor E.2.a/239/BAA-UMM/III/2020. Selain itu apresiasi yang tinggi kami berikan kepada Ibu Yanur Setyaningrum, M.Pd. selaku Kepala Sekolah SMP Muhammadiyah 1 Malang yang telah mendukung kegiatan pengadian ini sehingga berjalan dengan lancar.

\section{DAFTAR PUSTAKA}

Al-anwari, A. M. (2014). Strategi pembentukan karakter peduli lingkungan di sekolah adiwiyata mandiri. Ta'dib, 19(02), 227-252.

Aliman, M., Budijanto, Sumarmi, \& Astina, I. K. (2019). Improving environmental awareness of high school students' in Malang city through earthcomm learning in the geography class. International Journal of Instruction, 12(4), 79-94. http://doi.org/10.29333/iji.2019.1246a

Asy'ari, A., \& Abidin, R. (2019). Implementasi kebijakan sekolah adiwiyata sebagai upaya membangun karakter dan kepedulian lingkungan siswa SMP Negeri 23 Surabaya. In Prosiding Seminar Nasional Pendidikan KALUNI (Vol. 2, pp. 617-624). http://doi.org/10.30998/prokaluni.v2i0.155

Baharudin, M. D. F. (2017). Pelaksanaan program adiwiyata dalam mendukung pembentukan karakter peduli lingkungan. Jurnal Pendidikan Geografi, 17(1), 25-37.

Bergman, B. G. (2016). Assessing impacts of locally designed environmental education 
projects on students' environmental attitudes, awareness, and intention to act. Environmental Education Research, 22(4), 480-503. http://doi.org/10.1080/13504622.2014.999225

Boeve-de Pauw, J., Donche, V., \& Van Petegem, P. (2011). Adolescents' environmental worldview and personality: An explorative study. Journal of Environmental Psychology, 31(2), 109-117. http://doi.org/10.1016/j.jenvp.2010.05.003

Boeve-de Pauw, J., \& Van Petegem, P. (2011). The Effect of Flemish Eco-Schools on Student Environmental Knowledge, Attitudes, and Affect. International Journal of Science Education, 33(11), 1513-1538. http://doi.org/10.1080/09500693.2010.540725

Cheeseman, A., \& Wright, T. (2019). Examining environmental learning experiences at an earth education summer camp. Environmental Education Research, 25(3), 375-387. http://doi.org/10.1080/13504622.2018.1509301

do Carmo Galiazzi, M., Paula Salomão de Freitas, D., Aguiar de Lima, C., da Silva Cousin, C., Langoni de Souza, M., \& Launikas Cupelli, R. (2018). Narratives of learning communities in environmental education. Environmental Education Research, 24(10), 1501-1513. http://doi.org/10.1080/13504622.2018.1545152

Genc, M. (2015). The project-based learning approach in environmental education. International Research in Geographical and Environmental Education, 24(2), 105-117. http://doi.org/10.1080/10382046.2014.993169

Gould, R. K., Ardoin, N. M., Thomsen, J. M., \& Wyman Roth, N. (2019). Exploring connections between environmental learning and behavior through four everyday-life case studies. Environmental Education Research, 25(3), 314-340. http://doi.org/10.1080/13504622.2018.1510903

Munawar, S., Heryanti, E., \& Miarsyah, M. (2019). Hubungan pengetahuan lingkungan hidup dengan kesadaran lingkungan pada siswa sekolah adiwiyata. LENSA (Lentera Sains): Jurnal Pendidikan IPA, 9(1), 22-29. http://doi.org/10.24929/lensa.v1i1.58

Permana, B. I., \& Ulfatin, N. (2018). Budaya sekolah berwawasan lingkungan pada sekolah adiwiyata mandiri. Ilmu Pendidikan: Jurnal Kajian Teori Dan Praktik Kependidikan, $3(1), 11-21$.

Politikamalang. (2019). 36 Sekolah di Malang terima anugerah Adiwiyata Kota Malang 2018.

Radarmalang. (2019). Siapkan 18 sekolah tembus Adiwiyata Mandiri.

Schumm, M. F., \& Bogner, F. X. (2016). How environmental attitudes interact with cognitive learning in a science lesson module. Education Research International, 2016, 1-7. http://doi.org/10.1155/2016/6136527

Setiyowati, L. E. (2017). Pemberdayaan guru menuju Sekolah Adiwiyata di SD Negeri Sine 1 Sragen. Universitas Muhammadiyah Surakarta. Retrieved from http://eprints.ums.ac.id/48996/23/01. Naskah Publikasi.pdf

Steele, A., Hives, L., \& Scott, J. (2016). Stories of learning: Inquiry-based pathways of discovery through environmental education. Cogent Education, 3(1). http://doi.org/10.1080/2331186X.2016.1202546

Supriadi. (2020). Implementation of Demonstration Method to improve teacher knowledge of Adiwiyata School. Jurnal PAJAR ( Pendidikan Dan Pengajaran ), 4(1), 207-218. http://doi.org/10.33578/pjr.v4i1.7928

Widodo, H. (2017). Budaya sekolah adiwiyata (Studi kasus di SD Muhammadiyah Bodon Bantul Yogyakarta). Tajdidukasi, 7(1), 1-18. 